\title{
LA LEY GENERAL EN MATERIA DE TRATA DE PERSONAS COMO PARADOJA DEL DERECHO
}

\author{
Víctor Manuel RANGel CORTÉs ${ }^{1}$
}

Resumen: Objetivo: criticar el discurso de la Ley General para Prevenir, Sancionar y Erradicar los Delitos en Materia de Trata de Personas y para la Protección y Asistencia a las Víctimas de estos Delitos como instrumento de poder político. Metodología: método crítico analítico, a partir de las paradojas del derecho desarrollados por Sánchez Sandoval en su libro "Epistemologías y sociología jurídica del poder". Resultados: la construcción de la ley en contra de la trata de personas depende de los intereses políticos que la crearon, viola derechos humanos y no cumple con sus objetivos. Conclusión principal: la ley general en contra de la trata de personas es una paradoja ya que le da sentido a la fallida política criminal en la materia la cual viola derechos humanos y no resuelve la problemática.

Palabras Clave: Trata de personas; ley general; víctimas; poder político; discurso; epistemología; realidad; artificial; paradoja; derecho; delito.

Abstract: Purpose: to criticize the discourse of the General Law to Prevent, Punish and Eradicate Crimes in the Field of Human Traffickings and for the Protection and Assistance to the Victims of these Crimes as an instrument of political power. Methodology: critical analytical method, based on the paradoxes of law developed by Sánchez Sandoval in his book "Epistemologies and legal sociology of power". Results: the construction of the law against human trafficking depends on the political interests that created it, violates human rights and does not meet its objectives. Main conclusion: the general law against trafficking in persons is a paradox because it gives meaning to the failed criminal policy in the matter which violates human rights and does not solve the problem.

1 Doctor en Derecho por la Facultad de Estudios Superiores Acatlán de la Universidad Nacional Autónoma de México. Profesor de asignatura en el Posgrado en Derecho de la misma institución. Candidato a Investigador Nacional en el CONACYT. Asesor en la Comisión Contra la Trata de Personas del Senado de la República de 2012 a 2018. 
KeYwords: Human trafficking; general law; victims; political power; discourse; epistemology; reality; artificial; paradox; law; crime.

SUMARIO: I. Introducción. II. Qué es una paradoja. III. La ley en materia de trata de personas y sus paradojas. IV. Comentario final. V. Conclusiones. VI. Fuentes.

\section{INTRODUCción}

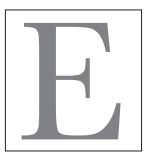

l objetivo del presente artículo es criticar el discurso de la Ley General para Prevenir, Sancionar y Erradicar los Delitos en Materia de Trata de Personas y para la Protección y Asistencia a las Víctimas de estos Delitos (ley general contra la trata de personas) como instrumento de poder político.

La trata de personas entendida como la captación de personas para ser sometidas a algún tipo de explotación constituye una actividad vieja. La venta de esclavos era parte de las actividades comerciales de sociedades de antaño. Por su parte, el comercio sexual, también, es considerado como una de las actividades que durante años ha sido parte del entorno social de la humanidad.

Actualmente, la trata de personas es una actividad con presencia en todo el mundo. De acuerdo Oficina de las Naciones Unidas contra las Drogas y el Delito (ONUDC), "Cada año, miles de hombres, mujeres y niños caen en manos de los traficantes, en sus propios países y en el extranjero". ${ }^{2}$ Esto proporciona una idea de la magnitud global del problema.

Según el Informe Global sobre Trata de Personas 2016 de la ONUDG México ocupa el lugar $5^{\circ}$ en la comisión de dicho delito. $\mathrm{Al}$ respecto, cabe señalar que gracias a su ubicación geográfica es

2 Oficina de las Naciones Unidas contra las Drogas y el Delito, Human Trafficking, Consultado el 18 de julio de 2018 en: <https://www.unodc.org/unodc/en/ human-trafficking/what-is-human-trafficking.html $>$. 
un país es considerado como de origen, tránsito y destino de las víctimas de trata de personas. ${ }^{3}$

La ley general contra la trata de personas actual entró en vigor en el 2012, de acuerdo con su nombre tiene por objeto la prevención, sanción y erradicación de los delitos en la materia, así como la protección y asistencia a las víctimas. A pesar de la existencia de esta legislación y de la aplicación de políticas públicas, en México se cometen violaciones a los derechos humanos en contra de sospechosos y no se logra, por lo menos, la disminución de la comisión de dicho problema; sin embargo, ante el evidente fracaso, el sistema político en su discurso invoca una serie de resultados favorables en contra de este delito.

En ese tenor, la hipótesis de este artículo es que: La ley general contra la trata de personas en México es una paradoja ya que le da sentido a la fallida política criminal en materia de trata de personas la cual viola derechos humanos y no resuelve la problemática.

Para lograr lo anterior se parte de la premisa de que México es un Estado neoliberal caracterizado por liberalización económica, el libre comercio, los mercados abiertos, la privatización, la desregulación y la disminución del tamaño del sector público mediante el incremento de la influencia del sector privado y su sistema jurídico se determina por esas mismas características. ${ }^{4}$

De acuerdo con González Vidaurri y Sánchez Sandoval, en el ámbito del derecho penal las políticas neoliberales se ven reflejadas

3 Cfr. Oficina de las Naciones Unidas contra las Drogas y el Delito, Informe Global sobre Trata de Personas 2016, Viena, ONU, 2016, p. 95.

4 Cfr. Augusto Sánchez Sandoval, Seguridad Nacional y Derechos Humanos, México, Facultad de Estudios Superiores Acatlán de la UNAM, 2013, pp. 107-109; Cfr. Jaime Fernando Cárdenas Gracia, El modelo jurídico del neoliberalismo, México, Instituto de Investigaciones Jurídicas de la UNAM, 2016, pp. 1-173; Cfr. Paul Cooney, Dos décadas de Neoliberalismo en México: resultados y retos en Novos Cadenos, NAEA, volumen 11, num. 2, pp. 15-41; Cfr. John Ackerman, El mito de la transición democrática, México, Planeta, 2015, pp. 320. 
en la creación de un sistema jurídico agresivo y violador de los derechos humanos de forma legal:

En la posmodernidad neoliberal la radicalización del sistema productivo está produciendo a su vez la radicalización del sistema político-jurídico penal y de represión incluso de hecho, pero ahora ya no es oculto, sino abierto, agresivo y cínico, porque convierte en derecho del dominante, aquello que la modernidad consideró violación de garantías individuales. ${ }^{5}$

De esta manera, México queda sometido un proceso de armonización legislativa nacional en materia de trata de personas a nivel internacional. Situación que se ve reflejada en el Protocolo para prevenir, reprimir y sancionar la trata de personas, especialmente mujeres y niños que deriva de la Convención de las Naciones Unidas contra la Delincuencia Organizada Transnacional. Ambos documentos, gracias a lo establecido por el artículo 133 de la Constitución Política de los Estados Unidos Mexicanos, son fundamento de la ley general contra la trata de personas. Particularmente, en el caso de la citada Convención, a decir de González Vidaurri y Sánchez Sandoval, en ella se establecen los principios del derecho penal de enemigo en el contexto neoliberal que a continuación se enuncian: ${ }^{6}$

1. Incriminación penal por solo sospecha.

2. No reconocimiento de los delitos políticos.

3. Utilización de agentes infiltrados.

4. Reducción y limitación de los beneficios penitenciarios.

5. Persecución abierta en el tiempo

5 Alicia González Vidaurri y Augusto Sánchez Sandoval, Criminología, México, Porrúa, 2013, p. 174.

6 Ibidem, p. 187. 
6. No reconocimiento del carácter fiscal exclusivo para un solo país de los bienes del reo, de los medios con que realiza los delitos y sus productos.

7. Competencia universal.

8. Negación de los secretos bancarios.

9. Aceptación de la analogía en materia penal.

10. Discrecionalidad de las autoridades.

11. Inversión de la carga de la prueba.

12. Extradición subsidiaria.

El enfoque teórico de esta investigación es crítico analítico, a partir de las paradojas del derecho desarrollados por Augusto Sánchez Sandoval en su libro "Epistemologías y sociología jurídica del poder". En las siguientes páginas, el trabajo se desarrolla de la siguiente manera: en el primer apartado se explica qué es una paradoja; posteriormente, se analiza la ley en materia de trata de personas a luz de las paradojas del derecho; finalmente, se presentan las conclusiones.

\section{Qué ES UNA PARADOJA}

Las relaciones sociales se reproducen a partir de las comunicaciones. Esto quiere decir que gracias a que podemos interactuar con los otros mediante el lenguaje, se establecen vínculos sociales. Es gracias al lenguaje que podemos transmitir nuestras experiencias, el conocimiento, una noticia o un sentimiento. Pero no solo se trata de simples comunicaciones, sino de un complejo sistema de transmisión de mensajes que al entrar en la conciencia del otro tienen efectos cognitivos:

Por otra parte está el mundo del lenguaje, que se inventa por los hombres en la comunicación, para construir la conciencia de 
lo real, la cual se institucionaliza y se reproduce a través de la ideología-norma. ${ }^{7}$

El mundo del lenguaje es aquel que los hombres inventan, solo existe en la mente o la conciencia de cada uno. Por ello, cuando se dice que cada quien tiene su verdad no se está tan equivocado. Cada individuo tiene la capacidad de interpretar el mundo real de acuerdo a sus puntos de vista, incluso de acuerdo a la posición que tenía en el momento de observar un objeto. Así, el mundo real es distinto, este no fue construido intelectualmente por el hombre, sino que fue creado por la naturaleza; sin embargo, el hombre y las sociedades interpretan ese realidad para construir una artificial que está de acuerdo a su propia ideología.

Cuando se habla de la verdad, solo hacemos referencia a un lenguaje creado por un hombre a través de su propia percepción, de sus propias ideologías y sus propios intereses. Por ejemplo, en un juicio, del sistema que sea, cada una de las partes defiende su postura, aunque se trate de alguien que sí es responsable de causar un daño, este dirá que las cosas sucedieron de una manera distinta.

Lo cierto es que en la estructura de la sociedad en que vivimos existen jerarquías determinadas por el poder y son estos individuos quienes construyen e imponen la verdad al resto de los sujetos:

C) La conciencia de la realidad del dominante, como racionalidad para todos. En toda persona, generalmente, se construye una conciencia de la realidad, pero en las sociedades verticales de dominación, el sujeto dominante impone su propia conciencia de realidad a todos los demás, y la institucionaliza como ideología obligatoria para todos y como la racionalidad general. ${ }^{8}$

Gracias a esta construcción, la verdad del poderoso se convierte en la verdad de todos los demás. Con esta acción se determina,

7 Augusto Sánchez Sandoval, Epistemologías y sociología jurídica del poder, México, UNAM-FES Acatlán, 2012, p. 25.

8 Ibidem, p. 53. 
mediante pautas, qué es lo bueno/malo, legal/ilegal y, también el amigo/enemigo. Por eso cuando el sistema político dice que tenemos derechos humanos gracias a que la Constitución lo dice, hay una disposición a creerlo y asumir que en México se vive en un Estado de Derecho aunque esos mismos derechos son violados sistemáticamente, incluso de forma prevista en ley. ${ }^{9}$

Así, el Derecho es un discurso que se construye a partir de la conciencia del dominante y que lo instituye como medio de control social:

Los sujetos con poder construyen el mundo del lenguaje político y lo institucionalizan a través de la violencia o de las ideologías-norma, para construir un sistema que opere mediante los aparatos ideológicos y los aparatos represivos del Estado. Con ello se busca mantener unido el todo, sobre el cual recae la dominación para reproducirlo

9 De acuerdo con el reporte 2015 de la Comisión Interamericana de Derechos Humanos, en México se comenten tortura, desapariciones forzadas, asesinatos de periodistas: "Este contexto de lucha contra el narcotráfico y la consecuente militarización de zonas del país ha resultado en varias ocasiones en un incremento de la violencia y de las violaciones a los derechos humanos, así como en mayores niveles de impunidad. Es decir, la atribución a las fuerzas armadas de roles que corresponderían a las fuerzas policiales civiles y el despliegue de operativos conjuntos entre las fuerzas armadas y las instituciones de seguridad estatales y municipales en distintas partes del país, han dado lugar a mayores violaciones de derechos humanos" Comisión Interamericana de Derechos Humanos, Reporte Situación de derechos humanos en México 2015, CIDH, 2016, p. 65. Consultado el 15 de julio de 2018 en: <http://www.oas.org/es/cidh/informes/pdfs/Mexico2016-es.pdf>.

En el mismo sentido Amnistía Internacional en su informe 2017-2018 señala que: "La violencia aumentó en todo México. Las fuerzas armadas seguían llevando a cabo labores habituales de la policía. Continuaron las amenazas, los ataques y los homicidios contra periodistas y defensores y defensoras de los derechos humanos; los ciberataques y la vigilancia digital eran especialmente habituales. Las detenciones arbitrarias generalizadas seguían derivando en torturas y otros malos tratos, desapariciones forzadas y ejecuciones extrajudiciales. Persistía la impunidad por violaciones de derechos humanos y crímenes de derecho internacional. [...]". Amnistía Internacional, Informe 2017/18: La situación de los derechos humanos en el mundo, p. 312. Consultado el 15 de julio de 2018 en: <https://www. amnesty.org/es/latest/research/2018/02/annual-report-201718/>. 
no sólo a través de la fuerza, sino también mediante la persuasión y el consenso para lograr el control social. ${ }^{10}$

Desde este punto de vista, el Derecho es parte del lenguaje emitido por sistemas como la política o el sistema económico. No emana de la voluntad del pueblo. El objetivo de estas comunicaciones es ejercer control social y legitimar el poder de quien lo ostenta. Podría decirse, que la política y el derecho, estructuralmente acoplados, construyen comunicaciones en donde se determina qué es lo legal/ ilegal. ${ }^{11}$ Lo cierto es que el Derecho, gracias a que es lenguaje, no puede garantizar que las cosas sucedan, esto quiere decir que solo se encuentra en la posibilidad de generar expectativas generadas por la política que funcionan como paliativo ante los problemas sociales que no se pueden resolver.

Pero si el Derecho es construido a partir de la visión del poderoso, quiere decir que ese lenguaje tiene como fin último, además del control social, la preservación de ese estatus de poderoso. Así, desde este punto de vista, la ley existe para satisfacer los intereses de los grupos en el poder o con alguna influencia en él. ${ }^{12}$

Ejemplo de lo anterior es la guerra contra el crimen organizado, misma que se ha desarrollado mediante la política, por demás simplista, de expedición de leyes. Esto quiere decir que ante la existencia de una situación problemática, el gobierno solo puede responder con la emisión de una ley. De esta manera, lo que hay en México es una política de reformismo penal que hace sentir a una parte de la sociedad civil que los problemas tienen la esperanza de acabar a corto plazo.

Si hay guerra contra el crimen organizado, entonces se crea la Ley Federal de Delincuencia Organizada y otras leyes para com-

10 Augusto Sánchez Sandoval, op. cit. p. 64.

11 Cfr. Niklas Luhmann, El derecho de la sociedad, México: Herder - Universidad Iberoamericana, 2005 p. $186-187$ y Cfr. Javier Nafarrete Torres, Niklas Luhmann, La política como sistema, México: Universidad Iberoamericana, 2009, 389-391.

12 Ibidem. p. 186-187. Paráfrasis. 
batir el secuestro, la trata de personas, las desapariciones forzadas, delitos electorales, de protección a testigos, lavado de dinero, extinción de dominio y otras que reflejan la política simbólica del sistema político ante la delincuencia. ${ }^{13}$ No obstante, a pesar de todo el discurso de abatir a los criminales y protección a las víctimas, a decir de Ávila, Martínez-Ferrer, Vera, Bahena y Musitu la gente, tanto la que ya ha sido victimizada como la que no, de ninguna manera se siente segura. ${ }^{14}$

Entonces, como el Derecho es un lenguaje que corresponde a los intereses de los poderosos, es paradójico. Esto significa que esa realidad construida por el Derecho aunque sea artificial, la sociedad le da vida, la dota de sentido, de tal forma que se vive en ese mundo como si de verdad existiera:

Para Paul Watzlawick la paradoja puede definirse como una contradicción que resulta de una deducción correcta, a partir de premisas congruentes. Y en términos de Raffaele De Giorgi la paradoja consiste en dar sentido a algo que no tiene sentido y vivir ese sin sentido $[\ldots]^{15}$

Como ya se mencionó, hoy el Derecho dice que tenemos derechos humanos, aunque se violen todos los días. Hay un sistema de tipo normativo que dice que el proceso penal será acusatorio; sin embargo, también hay un derecho penal del enemigo cuando se trata de delincuencia organizada. ${ }^{16}$ Se dice que hay democracia,

13 Winfried Hassemer, Derecho penal simbólico y protección de bienes jurídicos, Pena y Estado, Jurídica Conosur, 1995, pp. 23-36.

14 María Elena Ávila, Belén Martínez-Ferrer, Alejandro Vera, Alejandro Bahena y Gonzalo Musitu, Victimización, percepción de inseguridad y cambios en las rutinas cotidianas en México en Revista de Saúde Pública, 50, 60. Epub October 03, 2016. Paráfrasis.

15 Augusto Sánchez, op. cit, p. 200.

16 Por ejemplo, en el caso del artículo 2 de la Ley Federal Contra la Delincuencia Organizada autores como Polaino-Orts lo exponen como la materialización del derecho penal del enemigo por las siguientes razones: "La primera carac- 
aunque el proceso electoral está lleno de inconsistencias. ${ }^{17}$ Se habla de que hay avances en seguridad pública; no obstante, los índices criminalidad, como todos saben, no bajan.

Para Sánchez Sandoval el Derecho está lleno de paradojas, las cuales, de momento, solo se enuncian y que serán definidas en el siguiente apartado: ${ }^{18}$

1. El derecho carece de identidad ontológica

2. El poder que manipula el derecho, crea el delito al definirlo

3. El derecho no se controla a sí mismo

4. Si el derecho penal es preventivo, es abusivo

5. El derecho no se controla a sí mismo

6. Si el derecho penal es preventivo, es abusivo

terística del tipo penal de delincuencia organizada del art. 2 de la Ley mexicana es la técnica del adelantamiento de la punición. Esta técnica consiste, como ya ha quedado explicado, en la anticipación del momento en el que el Derecho penal entra en acción. Mientras que en los casos usuales o más frecuentes (a los que se llaman Derecho penal del ciudadano) el Derecho penal entra en funcionamiento cuando ya se ha lesionado o puesto en peligro un bien jurídico de carácter generalmente material (por ejemplo: cuando ya se ha producido una lesión o la muerte de un sujeto es cuanto retrospectivamente, se sanciona al autor por su delito ya pasado) en los casos de Derecho penal del enemigo se adelanta ese momento a un estadio anterior, lo cual introduce una perspectiva de mayor prevención frente a un riesgo ulterior que se quiere evitar incluso a costa de reducir el ámbito de libertad del sujeto." Polaino y Orts, Criminalidad organizada: fundamentos dogmáticos y límites normativos (con referencia a la Ley Federal mexicana contra la delincuencia organizada) en: Criminalidad organizada, formas de combate mediante el derecho penal, México, Flores, p. 98-99.

17 Cfr. Jaime Cárdenas Gracia, La crisis del sistema electoral mexicano: a propósito del proceso electoral 2012, México, UNAM, 2016 pp. 31 - 290. y Jaime Cárdenas Gracia, El proceso electoral de 2006 y las reformas electorales necesarias en Revista Mexicana de Derecho Constitucional, México, Número 16 Enero - Junio 2007, Instituto de Investigaciones Jurídicas-UNAM, pp. 43-69.

18 Augusto Sánchez Sandoval, op. cit., pp. 200-215. 
7. El estado de excepción es la eliminación del derecho, por el derecho mismo

8. El derecho se puede hacer y ejercer, como terrorismo jurídico

9. El poder y el derecho entran en una recursividad que los implica a los dos

10. El derecho es ideología y por lo tanto oculta su origen como constructor de pautas para excluir

11. El delito como imputación y no como transgresión.

12. El derecho es parcial y tiene interés político, aunque se afirme lo contrario

Bajo esta perspectiva, se puede concluir que gracias al lenguaje del Derecho quienes ejercen el poder se legitiman y generan estrategias de control social derivadas de la construcción de un mundo intelectual, por tanto artificial, impuesto a la sociedad que lo acepta $\mathrm{y}$ vive aunque solo se trate de expectativas de comportamiento.

III. LA LEY EN MATERIA DE TRATA DE PERSONAS Y SUS PARADOJAS

Como el Derecho es un lenguaje y está lleno de paradojas, entonces la Ley general en contra la trata de personas también lo es. Ya se dijo que México ocupa un lugar importante dentro de los países de América en donde se comete dicha conducta delictiva. La respuesta ante tal problemática fue, como en otros casos, emitir una ley que promete terminar con el problema.

1. Primera paradoja: El derecho carece de identidad ONTOLÓGICA

La ley general en materia de trata de personas pertenece al mundo del deber ser, lo que implica solo la creación de expectativas cuya materialización es contingente: 
1. El derecho carece de identidad ontológica. La diferencia "Ser" y Deber Ser" le sirve al derecho para inventar su origen. Es la paradoja que al distinguir oculta y produce información. El derecho no es un ser en el presente, sino un deber ser en el futuro, que podrá ser o no ser, que podrá cumplirse o no. $[\ldots]^{19}$

Lo anterior se traduce en que la ley no puede controlar los resultados de su aplicación, es más, es posible que ni siquiera se aplique o se aplique mal. Ejemplo de esto se encuentra en el nombre completo de la ley: Ley General para Prevenir, Sancionar y Erradicar los Delitos en Materia de Trata de Personas y para la Protección y Asistencia a las Víctimas de estos Delitos. Ya de entrada el sistema político y el jurídico prometen erradicar los delitos de la materia, lo cual puede resultar prácticamente imposible.

De acuerdo con la Comisión Nacional de los Derechos Humanos, con información del INEGI, UNICEF y DIF, se calcula que en México se someten a explotación sexual a 20,000 niños y niñas; asimismo, con base en información de SECTUR, el total de víctimas se estima entre los 50,000 y 500,000 casos. $^{20}$ En el mismo sentido Estrada Michel señala que:

Un diagnóstico realizado por la Organización de las Naciones Unidas y la Secretaría de Gobernación señala que en México cerca de 70 mil niños y niñas son víctimas de trata, cifra que lo posiciona a la cabeza de la trata de menores en América Latina. Asimismo, con base en el Human Trafficking Assesment Tool, de la American Bar Association $(\mathrm{aBa})$, en el país existen 47 bandas que se dedican a la trata sexual y laboral de personas, y asienta también que las entidades con mayor incidencia en este ilícito son Baja California, Chiapas, Chihuahua, Guerrero, Morelos, Oaxaca, Tlaxcala y Quintana Roo, así como el Distrito Federal. ${ }^{21}$

19 Ibidem, p. 200.

20 Comisión Nacional de los Derechos Humanos, Diagnóstico sobre la situación de la trata de personas en México, México, CNDH, 2013, p. 17.

21 Rafael Estrada Michel, Prologo en Aspectos sociales y culturales de la trata de personas en México, Coord: Casillas, Rodolfo R. Instituto Nacional de Ciencias Penales, 2013. p. 14. 
Las cifras son de 2013, la realidad es que a la fecha la situación no ha cambiado mucho. En la siguiente nota publicada en 2017 por el economista se refiere que:

El número de víctimas de trata de personas en México se estima en 500,000 casos, de los cuales alrededor de 70,000 son menores de edad sujetos a explotación sexual. En nuestro país existen 47 grupos de delincuencia organizada involucrados en la trata de personas para fines sexuales y laborales, de acuerdo con una investigación para el Instituto Belisario Domínguez del Senado de la República. ${ }^{22}$

Por su parte la Embajada de Estados Unidos en su reporte 2018 sobre trata de personas señala:

Como se viene informando los últimos cinco años, México es un país de origen, tránsito y destino de hombres, mujeres y niños víctimas de la trata sexual y de trabajo forzoso. ${ }^{23}$

De esta manera queda en evidencia que la ley en la materia no tiene la capacidad de resolver el problema al que se encuentra enfocada. La trata de personas es un contrariedad de tal magnitud que no puede ser resuelto con la simpleza del lenguaje jurídico. El Derecho, como dice Luhmann, es contingente, lo cual quiere decir que puede cumplir o no sus objetivos. ${ }^{24}$ Por eso, quienes la redactaron fueron demasiado ambiciosos o abusivos cuando intentaron decir que la ley podría erradicar el delito en cuestión.

Lo mismo sucede cuando la ley promete prevenir, investigar, perseguir y sancionar los delitos en ella establecidos:

22 Rubén Torres y Jorge Monroy, México sin cifras precisas sobre trata en El economista, México, Ciudad de México, 30 de julio de 2017,. Consultado en: <https://www.eleconomista.com.mx/politica/Mexico-sin-cifras-precisas-sobre-trata-20170730-0073.html>.

23 Embajada de Estados Unidos en México, Reporte sobre Tráfico de Personas 2018, Consultado el 20 de julio de 2018 en: <https://mx.usembassy.gov/es/ our-relationship-es/reportes-oficiales/reporte-sobre-trafico-de-personas/ $>$.

24 Niklas Luhmann, El derecho de la sociedad, México: Herder - Universidad Iberoamericana, 2005, pp. 186 y 187. 
Artículo 2o. Esta Ley tiene por objeto:

I. Establecer competencias y formas de coordinación para la prevención, investigación, persecución y sanción de los delitos en materia de trata de personas entre los Gobiernos Federal, de las entidades federativas y Municipales;

Lo anterior hace que el sistema político construya una realidad en la que se cumplen los objetivos de la legislación. Al respecto, en la ahora Ciudad de México las autoridades han expresado lo siguiente:

Juana Camila Rebollar, fiscal central de Investigación para la Atención del Delito de Trata de Personas de la Procuraduría capitalina, informó que en la lucha contra ese delito en la Ciudad de México se han desmantelado 85 bandas y obtenido 320 sentencias condenatorias contra los responsables del 2007 a la fecha, esto luego de dar a conocer el resultado de un operativo donde se liberó a 17 menores de edad explotadas sexualmente. ${ }^{25}$

Curiosamente, a pesar de lo que se señala en la nota, todos en la capital saben de los lugares en donde se comete trata de personas o explotación. Incluso, a un costado de la sede nacional del Partido Revolucionario Institucional es posible observar a mujeres que se prostituyen, seguramente algunas en contra de su voluntad. En efecto, de acuerdo con la Embajada de Estados Unidos, México no cumple ciertos lineamientos para enfrentar el problema:

El Gobierno de México no cumple plenamente con las normas mínimas para la erradicación de la trata de personas; sin embargo, está haciendo un gran esfuerzo por lograrlo. ${ }^{26}$

25 Rubén Torres y Jorge Monroy, op. cit.

26 Embajada de Estados Unidos en México, Reporte sobre Tráfico de Personas 2017. Consultado el 20 de julio de 2018 en: <https://mx.usembassy.gov/es/ our-relationship-es/reportes-oficiales/reporte-sobre-trafico-de-personas $>$. 
Aunque Estados Unidos reprueba a México, también hay que señalar un lenguaje políticamente correcto reconoce los esfuerzos que se hacen. Lo cierto es que no se cumplen los objetivos del artículo 2o de la ley:

El gobierno redujo el número de investigaciones y enjuiciamientos, pero condenó a más tratantes que en 2015. La destacada complicidad de las autoridades, en particular la policía y otras autoridades locales, en la comisión de delitos de trata menoscabó la labor de las fuerzas del orden.

En conclusión, la ley general en materia de trata de personas pertenece al mundo del deber ser, lo que implica solo la creación de expectativas cuya materialización es contingente al estar referidas al futuro y por ello no puede garantizar el cumplimiento de sus objetivos sobre erradicación, investigación, persecución y sanción de los delitos en materia de trata de personas.

2. Segunda paradoja: El poder que manipula el Derecho, CREA EL DELITO AL DEFINIRLO

Los delitos contenidos en ley general en materia de trata de personas son mal definidos de con base en los intereses de quien los creó:

2. El poder que manipula el derecho, crea el delito al definirlo; al nombrarlo construye el riesgo de que alguien identifique su conducta con la definición jurídica, y pueda caer en las manos de sus operadores y represores. ${ }^{27}$

Un aspecto digno de señalar es que en México la trata de personas ya contaba con legislación anterior a la ley de 2012. En el 2007 Felipe Calderón publicó la ley en materia de trata de personas, que contenía la definición legal de dicha conducta; sin embargo, esta legislación fue derogada tan solo cuatro años después en 2012. Una

27 Augusto Sánchez Sandoval, op. cit., p. 201. 
de la razones fue que el delito de trata de personas de la ley anterior contenía en su integración medios comisivos, como el engaño, que hacen difícil la labor de la autoridad investigadora:

Algo parecido sucede y no estoy imaginando porque así lo establece la exposición de motivos de la iniciativa de ley general que los medios comisivos, esos que claramente establece el protocolo, no deben formar parte de la redacción típica porque su acreditación sólo complica las cosas. ¿Y quién les dijo que la materia penal era fácil? El medio comisivo en materia de trata es de indispensable acreditación por parte del órgano investigador, pues sin su comprobación no puede demostrarse el sometimiento, y sin éste no hay trata de personas. ${ }^{28}$

En efecto, para facilitar la labor de investigación del delito se eliminaron los medios comisivos del delito de trata de personas al crear la ley de 2012:

Artículo 10.- Toda acción u omisión dolosa de una o varias personas para captar, enganchar, transportar, transferir, retener, entregar, recibir o alojar a una o varias personas con fines de explotación se le impondrá de 5 a 15 años de prisión y de un mil a veinte mil días multa, sin perjuicio de las sanciones que correspondan para cada

28 Miguel Ontiveros Alonso, El derecho penal frente a la trata de personas (problemas técnicos y político criminales) en <https://archivos.juridicas.unam.mx/www/bjv/ libros/7/3064/16.pdf>. En el mismo sentido el estudio realizado por Mónica Salazar señala: "Unas de las razones principales detrás de este reforma de 2012 era que el delito era sumamente difícil de probar, justificando así los pocos resultados que se obtenían. En específico, probar el sometimiento de una persona, por medio del engaño, la coacción, o cualquier otro elemento que la ley permitía, dificultaba su labor. Por ejemplo, una persona enganchada en Puebla a través del enamoramiento, que acepta trasladarse a la Ciudad de México con la que ella consideraba su pareja, y una vez ahí era sometida a través de amenazas con dañar a su familia en Puebla, para forzarla a la prostitución". Cfr. Hispanics in philanthrop, Una Mirada desde las organizaciones de la sociedad civil a la Trata de personas en México, Coord. Mónica Salazar, HIP, p. 13. Consultado en: <http://www.senado.gob.mx/comisiones/trata_personas/docs/trata.pdf>. 
uno de los delitos cometidos, previstos y sancionados en esta Ley y en los códigos penales correspondientes.

De esta forma, por ejemplo y sin entrar en detalles dogmáticos, el simple hecho de captar a una persona tal vez para llevarla en un taxi o darle trabajo ya haría a cualquiera susceptible de ser investigado. La cuestión es que el Fiscal o Ministerio Público no tiene la obligación de acreditar el cómo se hace esa conducta. Cabe hacer las siguientes preguntas ¿cómo se viola el bien jurídico tutelado por el delito? ¿La conducta de captar, enganchar o transportar causa alguna afectación? Incluso, la Suprema Corte de Justicia de la Nación en sus criterios ha señalado que los medios comisivos sirven para acreditar el sometimiento cognitivo, por virtud del cual es dominada la voluntad de la víctima, dirigida mediante una falsa representación de la realidad:

TRATA DE PERSONAS. CONFORME AL ARTíCUlO 3, INGISO B), DEL PROTOCOLO PARA PREVENIR, REPRIMIR Y SANCIONAR ESE DELITO, ESPECIALMENTE MUJERES Y NIÑOS, QUE COMPLEMENTA LA GONVENCIÓN DE LAS NAGIONES UNIDAS CONTRA LA DELINGUENGIA ORGANIZADA TRANSNAGIONAL (PROTOCOLO DE PALERMO), LA DEFENSA DEL ACTIVO BASADA EN QUE LA VÍCTIMA MAYOR DE EDAD CONSINTIÓ INICIALMENTE LA EXPLOTACIÓN SEXUAL A QUE FUE SOMETIDA, SE EXCLUYE GUANDO SE DEMUESTRA QUE PARA OBTENER EL CONSENTIMIENTO EL TRATANTE REGURRIÓ A GUALQUIERA DE LOS MEDIOS PROHIBIDOS (LEGISLAGIÓN DEL DISTRITO FEDERAL).

El delito de trata de personas previsto en el artículo 188 Bis del Código Penal para el Distrito Federal debe entenderse como un proceso que empieza con la captación de una persona, continúa con el traslado de ésta al lugar designado y sigue la fase de explotación, durante la cual la víctima se ve sometida a una servidumbre sexual, laboral o a otras formas de explotación. En este sentido, conforme al artículo 3, inciso b), del Protocolo para Prevenir, Reprimir y Sancionar la Trata de Personas, Especialmente Mujeres y Niños, que Complementa la Convención de las Naciones Unidas contra la Delincuencia Organizada Transnacional (Protocolo de 
Palermo), la defensa del activo basada en que la víctima mayor de edad consintió inicialmente la explotación pretendida, se excluye cuando se demuestra que para obtener el consentimiento el tratante recurrió a cualquiera de los medios prohibidos, como amenazas, fuerza, engaño, coacción o abuso de poder o de una situación de vulnerabilidad. De ahí que, si en el caso, la ofendida en un principio consintió trasladarse al Distrito Federal e incluso vivir en la casa de los activos del delito, en razón de la propuesta de trabajo como modelo que le hicieron vía internet; lo que, si bien pudiera ser un consentimiento o cooperación inicial entre la ofendida y los sujetos activos, lo cierto es que éste queda efectivamente anulado al encontrarse viciado, primero por el engaño y, posteriormente, por la coacción a través de la fuerza física y amenazas, para lograr la explotación sexual a que fue sometida. Por tanto, no puede tenerse como defensa situaciones de las que se advierta un aparente consentimiento de la víctima, puesto que éste debe considerarse viciado y, por ende, anulado, al probarse que los activos del delito utilizaron cualquiera de los medios prohibidos mencionados para obligar a la víctima a permanecer con ellos y explotarla sexualmente. ${ }^{29}$

Sumado a lo anterior, el Protocolo de Palermo en su definición de trata de personas establece la existencia de medios comisivos como elemento del delito:

Artículo 3

Definiciones

Para los fines del presente Protocolo:

a) Por "trata de personas" se entenderá la captación, el transporte, el traslado, la acogida o la recepción de personas, recurriendo a la amenaza o al uso de la fuerza u otras formas de coacción, al

29 Época: Décima Época, Registro: 2002428, Instancia: Tribunales Colegiados de Circuito, Tipo de Tesis: Aislada, Fuente: Semanario Judicial de la Federación y su Gaceta Libro XV, Diciembre de 2012, Tomo 2, Materia(s): Penal, Tesis: I.9o.P.21 P (10a.) Página: 1580. Amparo en revisión 79/2012. 28 de junio de 2012. Unanimidad de votos. Noveno Tribunal Colegiado en Materia Penal del Primer Circuito, Ponente: Emma Meza Fonseca. Secretaria: María del Carmen Campos Bedolla. 
rapto, al fraude, al engaño, al abuso de poder o de una situación de vulnerabilidad o a la concesión o recepción de pagos o beneficios para obtener el consentimiento de una persona que tenga autoridad sobre otra, con fines de explotación. Esa explotación incluirá, como mínimo, la explotación de la prostitución ajena u otras formas de explotación sexual, los trabajos o servicios forzados, la esclavitud o las prácticas análogas a la esclavitud, la servidumbre o la extracción de órganos $[\ldots]$

Igualmente, la ONUDC señala la misma integración y hasta cuenta con un check list que establece que la conducta de trata se constituye de acto-medio-fin. ${ }^{30}$

Contrario al efecto esperado por la supuesta facilidad de integrar investigaciones, a decir de la Embajada de los Estados Unidos, las cifras han disminuido:

Según datos basados en la amplia definición de la trata que contiene la ley de 2012, las autoridades iniciaron 188 investigaciones federales y 288 investigaciones estatales en 2016, comparadas con las 250 investigaciones federales y las 415 estatales por trata registradas durante 2015. Se iniciaron procesos penales contra 479 personas en los ámbitos federal y estatal en 2016, frente a 578 en los mismos ámbitos en 2015. Las autoridades informaron haber condenado a 228 tratantes en 127 causas de los ámbitos federal y estatal en 2016, frente a 86 en 36 causas de los mismos ámbitos en 2015. No obstante, no quedó claro cuántas de esas condenas guardaron relación con la trata conforme la define el derecho internacional. ${ }^{31}$

Como se puede apreciar, la ley, en particular el delito de trata de personas, ha sido manipulado y redactado dentro de un esquema de un derecho penal que es agresivo. Como lo señala Sánchez

30 ONUDC, Human Traffiking: <http://www.unodc.org/unodc/en/human -trafficking/what-is-human-trafficking.html? ref=menuside $>$ y Checklist Crim inazalization of Human Traffiking under the Protocol: <http://www.unodc.org/docu ments/ human-trafficking/Checklist $\% 20$ - $\% 20$ criminalization $\% 20$ under $\% 20$ the $\% 20$ Pro tocol.pdf $>$.

31 Embajada de Estados Unidos en México, op. cit. 
Sandoval una de las características del derecho penal del enemigo posmoderno es la construcción de delitos flexibles, es decir, que permitan encarcelar a los sospechosos de manera ágil en contravención al principio de presunción de inocencia. ${ }^{32}$ Esto se ve reflejado en el artículo 10 con la ausencia de los medios comisivos.

Pero demás, destaca el hecho de que, con base en las cifras señaladas por la Embajada de Estados Unidos, es posible decir que la ley no genera las números deseados por quienes pensaban que al disminuir los elementos del tipo penal eso sucedería. No obstante, la ley ha sido calificada como exitosa:

Muchas cosas han cambiado en estos 10 años gracias a la voluntad de autoridades comprometidas. El primer gran logro de esta causa es la Ley General para Prevenir, Sancionar y Erradicar los delitos en materia de Trata de Personas y para la Protección y Asistencia a las víctimas de estos delitos, la cual desde su promulgación en 2012 ha permitido perseguir y castigar verdaderamente este crimen. ${ }^{33}$

En el mismo sentido la Comisión Contra la Trata de Personas de la Cámara de Diputados de la LXIII Legislatura, ante la posibilidad de reformar la ley se manifestó por mantener el texto vigente:

En los años de vigencia de la Ley General para Prevenir, Sancionar y Erradicar los Delitos en Materia de Trata de Personas y para la Protección y Asistencia a las Víctimas de estos Delitos, del 2012 se han sentenciado a más de 600 delincuentes y muchos más se encuentran bajo proceso. Durante la vigencia de la Ley contra la Trata de Personas del 2007, se lograron tres sentencias, dos de las cuales se cayeron, afirma un estudio encargado por la comisión que

32 Alicia González Vidaurri y Augusto Sánchez Sandoval, op. cit., p. 174.

33 Rosi Orozco, Avances contra la trata en Milenio, México, Ciudad de México, 08 enero de 2016, Consultado el 29 de julio de 2018 en: <http://www.milenio. $\mathrm{com} /$ opinion/rosi-orozco/columna-rosi-orozco/avances-contra-la-trata $>$. 
preside la diputada Julieta Fernández (PRI) al asesor en materia de trata de personas de Fundación FIND, Cuauhtémoc Ibarra. ${ }^{34}$

Las declaraciones anteriores colaboran a la construcción de una realidad artificial sobre los efectos bondadosos de la ley general en contra de la trata de personas. Lo cierto es que, junto a lo dicho por la ley, son discursos construidos para lograr propósitos políticos, es claro que una persona que redactó la ley, tal vez hasta cobró, difícilmente aceptará que se equivocó. Por eso, para los actores políticos que la crearon y para los que viven en esa artificialidad la ley funciona y deben defenderla.

En conclusión, el delito de trata de personas contenido en la ley general está mal definido toda vez que fue creado con base en los intereses de los actores políticos que la crearon; sin embargo, aunque a ley flexibilizó la descripción típica del delito de trata para facilitar las investigaciones, no cumple con sus objetivos sobre erradicación, investigación, persecución y sanción de los delitos en materia de trata de personas.

3. Tercera paradoja: El derecho no se controla a sí MISMO

El contenido de la Ley general contra la trata de personas está construido a partir de los intereses de actores políticos:

3. El derecho no se controla a sí mismo. El sistema jurídico está penetrado por otros sistemas ajenos como el político, el económico, el religioso u otros sistemas de intereses. Por ello, si no puede controlarse hacia dentro, menos puede hacerlo hacia afuera. En consecuencia el derecho no es un sistema que controla la desviación

34 Jorge Monroy, Acusan regresión en Ley de trata en El Economista, Ciudad de México, 01 de enero de 2017. Consultado el 29 de julio de 2018: <https://www.eleconomista.com.mx/politica/Acusan-regresion-en-Ley-de-Trata-20170101-0084.html>. 
o el delito, sino una estructura selectiva dentro de la cual, se hace posible la desviación, el delito y la pena. ${ }^{35}$

Como cualquier legislación, la existencia y contenido de la ley general contra la trata de personas esta construido por intereses políticos y económicos. Aquí la primera pregunta es ¿Por qué si la ley anterior se había expedido apenas en 2007, por el mismo presidente, se tenía que hacer una nueva con tanta prisa? Esto es difícil de resolver, lo cierto es que en términos de discurso político hablar de protección a las víctimas de un delito es redituable, es muy difícil que un político se niegue a otorgar una ley que dice proteger a este sector. En el caso del presidente Calderón, hay que recordar que su sexenio se caracterizó por la guerra contra el crimen organizado, ante miles de muertos y en la antesala de una catástrofe electoral en la elección presidencial, sacar una ley cuyo discurso es meter a la cárcel a los delincuentes y muchos derechos para las víctimas posiblemente era negocio. ${ }^{36}$

¿Es posible tener un acercamiento a eses intereses en la redacción de la ley? la respuesta es sí. De inicio ya se mencionó en este mismo documento sobre la deficiencias dogmáticas del artículo 10 (piedra angular de la ley). Otro aspecto relevante es que la ley parece un compendio legislativo ya que es resultado de una mezcla de diversas legislaciones. Al revisarla, es posible encontrar contenido que corresponde a otros cuerpos normativos. En consecuencia, la ley

35 Augusto Sánchez Sandoval, op. cit., p. 205.

36 La ley habla de fondos pero hasta el 2015 según la embajada de Estados Unidos: "Los fondos del gobierno para servicios especializados y refugios para las víctimas permanecieron inadecuados, y estos servicios son prácticamente inexistentes en gran parte del país, lo que deja a un número importante de víctimas ya identificadas en situación vulnerable, y propensas a mayor victimización" Consultado en: <https://mx.usembassy.gov/es/mexico-reporte-de-trata-de-personas-2015/>. 
tiene disposiciones de derecho penal (delitos) procesales, atención y fondos para víctimas y política de prevención del delito. ${ }^{37}$

De acuerdo con los conceptos de la técnica legislativa descritos por Fernández Ruiz, cuando se expide una nueva ley, esta debe ser sistémica con la legislación preexistente; ${ }^{38}$ sin embargo, la ley contiene disposiciones de diversas materias que la hacen difícil de entender para las propias autoridades. Ejemplo de ello es la duda o confusión que se tenía sobre si la ley general debía aplicarse de forma directa al interior de las entidades federativas o debía ser la legislación local.

Esta confusión tuvo que ser resuelta por la Suprema Corte de Justicia de la Nación mediante el código binario: mitad sí/mitad:

Época: Décima Época; Registro: 2006148; Instancia: Pleno; Tipo de Tesis: Jurisprudencia; Fuente: Gaceta del Semanario Judicial de la Federación; Libro 5, Abril de 2014, Tomo I; Materia(s): Constitucional; Tesis: P./J. 25/2014 (10a.), Página: 405

DELitos GRAVES EN EL ESTADO DE COLIMA. EL ARTíCulo 10 DEL CÓdiGO PENAL PARA ESA ENTIDAD QUE LOS PREVÉ EN MATERIA DE TRATA DE PERSONAS Y DE SECUESTRO, EN SU TEXTO DERIVADO DEL DECRETO NO. 598, INVADE LA ESFERA DE ATRIBUCIONES DEL CONGRESO DE LA UNIÓN (LEGISLACión VIGENTE HaSTA EL 22 DE SEPTIEMbRE DE 2012).

El citado precepto en su texto derivado del Decreto No. 598, publicado en el Periódico Oficial de la entidad el 8 de septiembre de 2012, en las porciones normativas que indican "trata de personas, previsto en el artículo 161;", "secuestro y secuestro exprés previstos por los artículos 199 y 199 bis, respectivamente;", así como “... y secuestro" -en la parte referida a la tentativa-, invade la esfera de atribuciones del Congreso de la Unión, pues el legislador local es

37 Cfr. Víctor Manuel Rangel Cortés, La ley contra la trata de personas en el sistema jurídico mexicano, Comisión Contra la Trata de Personas, Senado de la República. Consultado el 29 de julio de 2018 en: <http://www.senado.gob.mx/comisiones/ trata_personas/docs/info_reformas5.pdf $>$.

38 Jorge Fernández Ruiz, El Poder Legislativo, México, Porrúa-UNAM, 2004 p. 451 y 452. Paráfrasis. 
incompetente para legislar en materia de trata de personas y secuestro, al haber quedado estas materias reservadas exclusivamente para el indicado órgano federal, mediante las reformas a la fracción XXI del artículo 73 de la Constitución Política de los Estados Unidos Mexicanos, publicadas en el Diario Oficial de la Federación el 4 de mayo de 2009, por lo que se refiere al secuestro, y el 14 de julio de 2011 , en lo relativo a la trata de personas. ${ }^{39}$

¿Por que surge la problemática anterior? de la lectura del citado criterio jurisprudencial se advierte que una parte de la ley fue expedida por el Congreso de la Unión sin tener facultades para ello. ${ }^{40}$ Una de las características de las leyes generales es que inciden en el ámbito de competencia de las entidades federativas; sin embargo, para ello se requiere que la Constitución otorgue esa facultad al Poder Legislativo Federal. ${ }^{41}$

Lo anterior derivado del numeral 26 inciso c) de la Ejecutoria correspondiente a la acción de inscontitucionalidad 54/2012 que refiere:

c) De este modo, se privó a los Estados de la República de la atribución que anteriormente tenían para legislar en materia del delito de trata de personas; manteniendo sin embargo, facultades para prevenir, investigar y castigar el referido delito, conforme al régimen de

39 Acción de inconstitucionalidad 54/2012. Procuradora General de la República. 31 de octubre de 2013. Unanimidad de diez votos de los Ministros Alfredo Gutiérrez Ortiz Mena, José Ramón Cossío Díaz, Margarita Beatriz Luna Ramos, José Fernando Franco González Salas, Arturo Zaldívar Lelo de Larrea, Jorge Mario Pardo Rebolledo, Luis María Aguilar Morales, Sergio A. Valls Hernández, Olga Sánchez Cordero de García Villegas y Juan N. Silva Meza. Ausente: Alberto Pérez Dayán. Ponente: José Ramón Cossío Díaz. Secretarios: Laura Patricia Rojas Zamudio y Raúl Manuel Mejía Garza.

40 Cfr. Fernández, Ruiz, Jorge, op. cit., p. 308.

41 La Suprema Corte de Justicia ha establecido que las leyes generales son aquellas que inciden en el ámbito de las entidades federativas. Cfr. Semanario Judicial de la Federación XXV, Registro: 172739, Instancia: Pleno, Materia(s): Constitucional, Tesis Aislada, Novena Época, Abril de 2007, Tesis: P. VII/2007, p. 5). 
concurrencia de facultades derivado de lo establecido en la fracción XXI del artículo 73 constitucional. ${ }^{42}$

En su momento, el artículo 73 constitucional solo otorgó la facultad al Congreso de la Unión para legislar en materia de delitos de trata de personas, pero no en materia de delitos de explotación, víctimas, política de prevención o fondos económicos. ${ }^{43} \mathrm{~A}$ pesar de este problema, la ley fue expedida. Otro aspecto importante es que desde la perspectiva de la ley, la trata de personas no se limita al contenido del artículo 10, sino que incluye otras conductas delictivas que en realidad son explotación. El problema es que la ley no hace una distinción y le otorga la misma conceptualización a todo, lo cual puede implicar problemas para el diseño y aplicación de política criminal.

Además, cabe apuntar, nuevamente, que el delito de trata de personas del artículo 10 se aparta de las normas internacionales. Situación que ha derivado en observaciones por parte de Estados Unidos desde 2015 a la fecha:

[...] modificar las leyes contra la trata a nivel federal y estatal para armonizarlas con las leyes internacionales; ${ }^{44}$

Un aspecto que llama mucho la atención es que en las dos Cámaras del Congreso de la Unión hay consenso en la necesidad de

42 Ejecutoria de la Acción de inconstitucionalidad 54/2012 promovida por la Procuradora General de la República, Décima Época. Pleno. Gaceta del Semanario Judicial de la Federación, Libro 3, Febrero de 2014, Tomo I, Pág. 123. Registro 24831.

43 El texto de la fracción XXI, párrafo primero, en el 2012 era el siguiente: "XXI. Para establecer los delitos y las faltas contra la Federación y fijar los castigos que por ellos deban imponerse; expedir leyes generales en materias de secuestro, y trata de personas, que establezcan, como mínimo, los tipos penales y sus sanciones, la distribución de competencias y las formas de coordinación entre la Federación, el Distrito Federal, los Estados y los Municipios; así como legislar en materia de delincuencia organizada."

44 Embajada de Estados Unidos, Reporte 2018, op. cit. 
reformar la ley. En el 2013 en el Senado de la República se presentó una iniciativa que contaba con el respaldo de la mayoría de los senadores. En ese mismo sentido, la reforma fue aprobada por las Comisiones legislativas involucradas. Lógicamente, el Pleno del Senado dio su aval sin votos en contra para que la reforma pasara a la Cámara de Diputados con la siguiente votación:

Tabla 1. Votación unánime en el Senado a la reforma a la ley general contra la trata. Elaborado por Víctor Manuel Rangel Cortés con datos del Senado ${ }^{45}$

\begin{tabular}{cc}
\hline Partido & Votos a favor \\
\hline PRI & 46 \\
PAN & 32 \\
PRD & 16 \\
PVEM & 4 \\
PT & 5 \\
\hline
\end{tabular}

La reforma aprobada por los senadores planteaba un cambio casi en su totalidad, la votación antes citada refleja que había consenso en ello; sin embargo, la Cámara de Diputados devolvió la reforma a la de origen con la siguiente votación:

45 Votación del dictamen aprobado por el Pleno del Senado de la República en sesión del 12 de febrero de 2014. Consultado el 29 de julio de 2018 en: <http:/ / www.senado.gob.mx/index.php? watch=36\&sm $=3 \& a n o=2 \& \mathrm{tp}=\mathrm{O} \& \mathrm{np}=$ $2 \& \lg =62 \& g \mathrm{p}=$ TOTAL\&id $=2012>$. 
Tabla 2. Votación por mayoría relativa en la Cámara de Diputados a la reforma a la ley general contra la trata. Elaborado por Víctor Manuel Rangel Cortés con datos de la Cámara de Diputados ${ }^{46}$

\begin{tabular}{ccc}
\hline Partido & Votos a favor & Votos en contra \\
\hline PRI & 162 & 0 \\
PAN & 2 & 71 \\
PRD & 51 & 6 \\
PVEM & 13 & 0 \\
PT & 9 & 0 \\
PNA & 5 & 0 \\
MG & 13 & 0 \\
SP & 0 & 0 \\
\hline
\end{tabular}

Lo que llama la atención es que las dos Cámaras están de acuerdo en que la ley debe ser reformada. El problema, al menos en apariencia, es que cada órgano legislativo tiene su propio criterio en el cómo debe ser reformada la ley. Por esa razón la reforma fue devuelta a la Cámara de origen hasta quedar pendiente en la Cámara de Diputados.

Un punto que resalta es que con todo este ir y venir, el diputado César Camacho, coordinador de la fracción del PRI, presentó, de forma posterior, una nueva iniciativa en la que propone una nueva ley general y desechar los avances del proceso legislativo anterior ¿qué interés político había en esto? es difícil determinarlo, lo cierto es que el legislador en cita fue candidato para senador en el proceso electoral de ese mismo año. Hasta la fecha la ley contiene las mismas deficiencias con las que nació.

46 Votación del dictamen aprobado por el Pleno de la Cámara de Diputados en sesión del 4 de diciembre de 2014. Fue devuelto a la Cámara de Senadores con modificaciones para los efectos para los efectos de lo dispuesto en el artículo 72, inciso e) de la Constitución Política de los Estados Unidos Mexicanos. Consultado el 29 de julio de 2018 en: <http://gaceta.diputados.gob.mx/>. 
¿En dónde está la disyunción entre las dos Cámaras? Justamente, en el debate sobre la inclusión de los medios comisivos como elemento esencial del tipo penal. Mientras que la reforma aprobada por la Cámara de Senadores los incluye de conformidad con las normas internacionales, las modificaciones de la Cámara de Diputados los elimina y redacta un tipo penal aún más ambiguo que el vigente. ${ }^{47}$

Los intereses son importantes, la trata de personas es un tema sensible y que tiene un impacto importante en la opinión pública. Tal fue el caso de opiniones como la siguiente:

$[\ldots]$

Avance insuficiente

La exdiputada y activista contra la trata de personas, Rosi Orozco, aseguró que la legislación aprobada mejora en aspectos como protección a la niñez. "Felicito a los senadores de las comisiones que verdaderamente hicieron muchísimo por evitar el retroceso y hacer cosas que son de avance", aseguró en entrevista con CNNMéxico. Sin embargo, informó que hay partes de la legislación que su organización Unidos contra la trata encuentra no convenientes.

"Nos preocupa que sean derogados el 19 y el 20 que vienen de la ley australiana y que son los artículos que nos permitían hacer muy fácil el acceso a la justicia para las víctimas porque si a alguien le dicen vas a ser edecán, llega y acaba en un prostíbulo, termina esto muy fácil esto en una sentencia y eso que lo hayan derogado no lo comprendemos", dijo Rosi Orozco en entrevista.

Actualmente, el artículo 19 señala "será sancionado con pena de 5 a 10 años de prisión y de 4,000 a 30,000 días de multa, el que contrate a una persona $\mathrm{u}$ oferte un trabajo distinto a los servicios sexuales y le induzca a realizarlos bajo el engaño".

Mientras que el 20 señala que se sancionará a quien contrate aún sea lícitamente a otra para la prestación de servicios sexuales.

47 Dicha situación puede ser corroborarse en el último dictamen aprobado por el pleno del Senado de la República el 27 de octubre de 2016 en:<http:// www.senado.gob.mx/index.php? $\mathrm{ver}=\mathrm{sp} \& \mathrm{mn}=2 \& \mathrm{sm}=2 \& \mathrm{id}=66865>$. 
Los legisladores consideraron que los artículos "carecen de sustento técnico y dogmático y que reproducen lo ya contemplado en otros artículos de esta ley", por lo que pidieron eliminarlos.

Unidos contra la Trata también consideró que la modificación hecha al artículo 10 es imprecisa pues quita la oración "toda acción u omisión dolosa de una o varias personas" con lo que quita el castigo a la permisión de las autoridades. $[\ldots]^{48}$

Tal y como dice el citado artículo, la exdiputada fue quien encabezó la iniciativa de la cual derivo la ley vigente. Además, cuenta con una asociación importante de atención víctimas de esos delitos, lo cual puede implicar recursos públicos. De tal forma que la opinión, sin decir que sea de mala fe, carece de objetividad. Además, de que como ha señalado la Embajada de Estados Unidos en su reporte 2018, los delitos en la ley son ambiguos:

Sin embargo, la ley es demasiado ambigua, ya que establece el uso de fuerza, el fraude, y la coerción como agravantes, en lugar de situarlos como elementos esenciales del crimen de trata; asimismo, define el facilitar u obtener ganancias por la prostitución de otros, la adopción ilegal, y la posesión y distribución de pornografía infantil como formas de trata. ${ }^{49}$

En conclusión, el contenido de la ley general contra la trata de personas cuyo objetivo es prevenir, sancionar y erradicar los delitos en materia de trata de personas, así como la protección y asistencia a las víctimas es un sin sentido, ya que, en tanto derecho, no puede controlar su contenido ni sus efectos al estar construida a partir de los intereses de actores políticos, lo cuales construyen una realidad en torno a su eficacia.

48 El Senado aprueba reforma a ley contra la trata que amplía tipificaciones en CNN México, México, 12 de febrero de 2014. Consultado el 15 de julio de 2018 en: <https://expansion.mx/nacional/2014/02/12/el -senado-aprueba-reforma-a-ley-contra-la-trata-que-amplia-tipificaciones $>$.

49 Embajada de Estados Unidos en México, Op. cit., p. 301. 
4. Cuarta paradoja: Si el derecho penal es preventivo, ES ABUSIVO

La ley en materia de trata de personas al pretender erradicar, sancionar y prevenir, se convierte en un derecho penal violador de derechos humanos:

5. Si el derecho penal es preventivo, es abusivo. El derecho que se fundamenta en la prevención, permite que la autoridad actúe sin que haya conducta y tampoco transgresión de un mandato. Es el derecho de las dictaduras y de los estados jurídicos de excepción, porque justifica el abuso de poder. Así, ocurre con las presunciones de peligrosidad social y las detenciones por sospecha; con los arraigos; con los cateos indiscriminados de personas y domicilios; con la intervención de las comunicaciones privadas, o la denuncia anónima, entre otros. ${ }^{50}$

Ya con anterioridad se señaló que la ley, sobre todo el artículo 10 , sanciona una conducta que no es trata de personas, toda vez que al faltarle un elemento como son los medios comisivos, estamos ante otra conducta, la cual es posible que ni siquiera implique una afectación.

El sistema político ha considerado que los operativos que aparecen en la televisión o en los periódicos causan una buena impresión en la opinión pública. Lo cierto es que son operativos que violan el principio de presunción de inocencia. Como todos saben, dicho principio se traduce en que nadie puede ser juzgado o ser considerado culpable de un delito sin que se le compruebe ello en un juicio con ciertas condiciones; sin embargo, sobre todo en lugares como la Ciudad de México se realizan operativos en centros que se consideran propicios para que se lleve a cabo la trata de personas o la explotación sexual.

50 Augusto Sánchez Sandoval, op. cit. p. 202. 
El principio bajo el que se realizan estos operativos es el de presunción de culpabilidad lo cual, en términos de Ferrajoli, se viola el principio garantista de "no se puede ser castigado por lo que se es, sino por lo que se ha hecho". ${ }^{51}$ De esta forma, la autoridad investigadora llega a los centros nocturnos y detiene a todos las personas posibles. Esto incluye bailarinas, meseros, choferes y todo aquel que se encuentre dentro. Por su parte la Embajada de Estados Unidos en su reporte de 2018 señala que:

[...] verificar mediante mayor capacitación y monitoreo que a las víctimas no se les obligue a testificar contra los tratantes, ni que se les trate a ellos mismos como tratantes; $[\ldots]^{52}$

¿Por qué una víctima tiene miedo de que se la trate como un tratante? porque como todos son culpables hasta que demuestren lo contrario, entonces la calidad de víctima es contingente, esto quiere decir que aunque una personas sea víctima existe una muy alta probabilidad de que en cualquier momento se convierta en tratante. De esta manera o cuenta como número a favor en el rubro de víctimas rescatadas o en el de tratante detenido y así se construye una realidad artificial en la que, según la subjetividad de la autoridad se combate eficientemente el delito.

La ley en su afán de prevenir y erradicar, gracias a su ambigüedad permite que se inicien muchas investigaciones y procesos judiciales; sin embargo, es difícil que se dé a conocer una estadística que refiera la cantidad de personas que salieron libres por no existir elementos que comprobarán su responsabilidad en cualquiera de los diversos momentos procesales en los que existe esa posibilidad:

$51 C f$ r. Luigi Ferrajoli, Jurisdicción y ejecución penal. La cárcel: una contradicción institucional en Crítica Penal y Poder num: 11, OSPDH-Universidad de Barcelona 11, 2016, p. 3.

52 Embajada de Estados Unidos en México, op. cit., p. 302. 
No queda claro cuántas de estas condenas se dieron por trata tal cual la define el protocolo de la ONU del 2000, y los funcionarios no reportaron el rango de las sentencias. ${ }^{53}$

La realidad es que una persona bajo investigación, privada de su libertad y, en su caso, sancionada con base en una ley ambigua, se le violan sus derechos humanos. En este caso hay que recordar que la Constitución Política de los Estados Unidos Mexicanos, en su artículo 14 establece el principio de seguridad jurídica en su vertiente de taxatividad:

Artículo 14. A ninguna ley se dará efecto retroactivo en perjuicio de persona alguna.

Nadie podrá ser privado de la libertad o de sus propiedades, posesiones o derechos, sino mediante juicio seguido ante los tribunales previamente establecidos, en el que se cumplan las formalidades esenciales del procedimiento y conforme a las Leyes expedidas con anterioridad al hecho.

En los juicios del orden criminal queda prohibido imponer, por simple analogía, y aún por mayoría de razón, pena alguna que no esté decretada por una ley exactamente aplicable al delito de que se trata.

En los juicios del orden civil, la sentencia definitiva deberá ser conforme a la letra o a la interpretación jurídica de la ley, y a falta de ésta se fundará en los principios generales del derecho.

En razón de lo anterior, la ley penal debe ser redactada de forma clara y precisa, la ambigüedad de la norma genera violaciones a ese principio y por ende a los derechos humanos. ${ }^{54} \mathrm{~A}$ ello hay que

53 Idem. Lo mismo se señala en reportes como el publicado por HIP Una mirada desde la sociedad civil a la trata de personas en México Coord. Mónica Salazar, Edición Dana Preston y Marcela Buzo: "en no todas han sido sentenciadas como tratantes, en realidad muchas de ellas han sido absueltas por falta de pruebas" p. 13.

54 De acuerdo con Roxin: "la prohibición de preceptos penales, indeterminados no sólo concuerda con el tenor literal de la Constitución, sino que se corresponde por completo igualmente con la finalidad del principio de legalidad. Una ley indeterminada o imprecisa y por ello poco clara no puede proteger al ciudadano 
sumar el hecho de que para reflejar sus resultados, la ley general en materia de trata de personas requiere ser materializada, es decir, para decir que hay una lucha contra los tratantes se requiere construir al supuesto tratante y encarcelarlo. De ahí su naturaleza represora.

Consecuentemente, la ley general en materia de trata de personas dados su objetivos políticos de prevenir y erradicar el delito, es un derecho penal construido para justificar las políticas públicas represivas y violadoras de derechos humanos que construyen un mundo artificial en el que se combate con eficacia la trata de personas.

\section{Quinta paradoja: El estado de excepción es la ELIMINACIÓN DEL DERECHO, POR EL DERECHO MISMO}

La paradoja anterior deriva en la posibilidad de que los derechos humanos sean suspendidos de forma arbitrara por el mismo derecho:

El estado de excepción constituye una circunstancia en que los derechos de los ciudadanos desaparecen, en virtud del mismo derecho, para dejar vigente sólo los derechos de los dominantes. Por ello, el derecho legitima a los grupos hegemónicos, se impone a toda la sociedad como único derecho en nombre de la libertad, de la seguridad y de la democracia, aunque los ciudadanos carezcan de todas ellas. ${ }^{55}$

La ambigüedad que ya se ha señalado en el delito de trata de personas, artículo 10, implica que al violarse el principio de segu-

de la arbitrariedad, porque no implica una autolimitación del ius puniendi estatal a la que se pueda recurrir; además es contraria al principio de división de poderes, porque le permite al juez hacer cualquier interpretación que quiera e invadir con ello el terreno legislativo; no puede reconocer lo que se le quiere prohibir; y precisamente por eso su existencia tampoco puede proporcionar la base para un reproche de culpabilidad». Cfr. Glaus Roxin, Derecho penal. Parte general. Fundamentos. La estructura de la teoría del delito, Thomson Civitas, Madrid, 2008, p. 345.

55 Augusto Sánchez Sandoval, op. cit, p. 202. 
ridad jurídica, entonces cualquier investigación, juicio y sentencia dictada con base en esa premisa viola los derechos humanos. Pero a ello hay que sumar que los delitos contenidos en la ley se persiguen de oficio y de acuerdo con el artículo 19 constitucional procede la prisión preventiva de la libertad de forma oficiosa.

De esta manera, es factible quitar su libertad a personas que sin cometer delitos de trata de personas conforme a las normas aceptadas en todo el mundo, puede ser encarcelada, pero esta privación no puede ser considerada ilegal porque la propia Constitución prevé esa violación. Adicionalmente, hay que tomar en cuenta que la trata de personas puede ser investigada y procesada en términos de la Ley Federal de Delincuencia Organizada. Si esto último sucede, entonces proceden medidas de excepción que pueden ser identificadas como un derecho penal del enemigo como el arraigo, la intervención de comunicaciones:

[...] Particularidades típicas del Derecho penal de enemigos son: 1) amplio adelantamiento de la punibilidad, es decir, el cambio de la perspectiva del hecho producido por la del hecho que se va a producir, siendo aquí ejemplificadose los tipos de ceración de organizaciones criminales o terroristas (129 y 129 a StGB), o de producción de narcóticos por bandas organizadas (30 I 1 y 31 I 1 BtMG); 2) falta de una reducción de la pena proporcional de dicho adelantamiento, por ejemplo, la pena para el cabecilla de una organización terrorista es igual a la del autor de una tentativa de asesinato, por su puesto aplicando la aminoración de la tentativa (SS 129 a II, 211 I y 49 I 1 StGB) y sobrepasa de manera ostensible en la mayoría de los casos las penas reducidas de la tentativa prevista para los demás delitos de asociaciones terroristas; 3 ) paso de la legislación de Derecho penal a la legislación de la lucha para combatir la delincuencia, y, en concreto, la delincuencia económica [...] 4) supresión de garantías procesales, donde la incomunicación del procesado constituye actualmente el ejemplo clásico. ${ }^{56}$

56 Jakobs Gunther, Moderna Dogmática penal, México, Porrua, 2006, p. 735 y 733. 
La existencia de esta legislación ha encontrado su justificación en un discurso político cuyo eje central es la protección de la víctima, aunque no la proteja. ${ }^{57}$ Esto quiere decir que el afectado por el delito sirve como un mecanismo de terapia de shock para que la sociedad conmovida por la situación de las víctimas, acepte y vea con beneplácito la suspensión de sus derechos aún y cuando lo que se pretenda sea perseguir simples sospechosos. ${ }^{58}$

En consecuencia, la ley general contra la trata de personas es un discurso que gracias a los intereses del sistema político crea un estado de excepción que se traduce en la suspensión de los derechos humanos de quienes resultan simples sospechosos de cometer un tipo penal ambiguo y con ello se viola el principio de presunción de inocencia.

6. Sexta paradoja: El derecho se puede hacer y ejercer, COMO TERRORISMO JURÍDICO

Gracias a su ambigüedad y al estado de excepción determinado por la ley general contra la trata de personas, las autoridades promueven políticas públicas basadas en el miedo del sector que resulta sospechoso de ser tratante:

7. El Derecho se puede hacer y ejercer, como terrorismo jurídico, por parte de sus operadores en el gobierno, en nombre del principio de inocencia. Los legisladores, los ministerios públicos y los jueces al servicio de los grupos hegemónicos han logrado construir y aplicar

57 Reporte 2017 de la Embajada de Estados Unidos: El gobierno identificó menos víctimas y prestó servicios especializados limitados a las víctimas de trata identificadas. Los albergues siguieron siendo insuficientes para la magnitud del problema y no había servicios para las víctimas en gran parte del país, por lo que algunas víctimas eran vulnerables a ser explotadas nuevamente.

58 Cfr. Naomi Klein y Isabel Fuentes García, La doctrina del shock: el auge del capitalismo del desastre, Barcelona: Paidós, 2007, p. 7-10. 
un derecho de excepción permanente frente al cual los ciudadanos quedan desnudos de derechos, gracias al mismo derecho. ${ }^{59}$

En la paradoja anterior, se decía del estado de excepción legalizado, pero ello no solo queda en el contenido de la ley, sino que de esa manera los operativos policiales que violan los derechos humanos de los sospechosos adquieren la cualidad de ser legales y con ello se legitiman dichos abusos de poder. Entonces, tales operativos se basan en el miedo.

Este miedo se ve reflejado en la propia víctima. De acuerdo con la Embajada de Estados Unidos en México las víctimas de trata:

[...] tuvieron miedo de identificarse como tales, y pocas presentaron denuncias o ayudaron en investigaciones y juicios por temor a represalias de los tratantes, la carencia de servicios especializados y la falta de confianza en las autoridades. Si bien las leyes mexicanas protegen a las víctimas contra la penalización por actos ilícitos cometidos como consecuencia directa de su sometimiento a la trata, las ONG informaron que, en la práctica, las víctimas acababan siendo detenidas o sancionadas ilegalmente por algunos funcionarios. ${ }^{60}$

Para la persona que es considerada víctima su primer miedo es al tratante, lo cual puede resultar hasta cierto punto lógico. La pregunta es ¿por qué a la autoridad? como se señala en la cita anterior, las víctimas terminan por ser detenidos o sancionados, es decir, la investigación se da en términos de: si no eres víctima, entonces eres tratante. Evidentemente, en casos como este la reacción de la víctima se basa cognitivamente en el miedo a ser detenido, por lo tanto prefiere ser víctima:

Según alegaron algunas personas dedicadas a la prostitución en la Ciudad de México, las autoridades las detenían y las obligaban a firmar declaraciones de acusación por trata contra detenidos, lo que suscitó gran preocupación por las tácticas de las fuerzas del or-

59 Augusto Sánchez Sandoval, op. cit., p. 203.

60 Embajada de Estados Unidos, op. cit. 
den para conseguir pruebas. Varias ONG también informaron que las autoridades a menudo traumatizaban nuevamente a las víctimas por su falta de sensibilidad. ${ }^{61}$

Lo grave es que la política pública construye víctimas, esto quiere decir que la autoridad las crea aunque, no necesariamente existen para justificar sus acciones. Pero cuando se construye una categoría, también se construye a su contraparte, por ejemplo, si digo que algo es legal, debe existir lo ilegal y se crea el código: legal/ilegal. Igualmente, si invento que hay una víctima, entonces al mismo tiempo se construye la categoría del victimario. Por ello, estos operativos están enfocados en la construcción cognitiva de víctimas y tratantes.

Como la ley es represiva y la política criminal también, los resultados arrojados por las autoridades en su combate son medidos con base en el número de investigaciones, detenidos y procesos judiciales que se inician y las detenciones se convierten en herramientas mediáticas. ${ }^{62}$ Por ello, Estados Unidos entre sus recomendaciones señala que México debe "intensificar las labores para investigar y enjuiciar a los sospechosos de delitos de trata y condenar a los tratantes, en especial por delitos de trabajo forzado". ${ }^{63}$

No extraña, entonces, que uno de los rubros importantes en el informe anual que debe presentar la Comisión Intersecretarial para Prevenir, Sancionar y Erradicar los Delitos en Materia de Trata de Personas y para la Protección y Asistencia a las Víctimas de la SEGOB tiene que ver con investigaciones y procesos judiciales. A pesar de lo alentadoras que resultan, tales cifras pueden ser esquizofrénicas dado que los datos presentados no coinciden entre

61 Idem.

62 Majo Siscar, Más detenciones pero menos responsables de trata en el DF en Animal político, México, Ciudad de México12 de agosto de 2014 en: <htt ps://www.animalpolitico.com/2014/08/mas-detenciones-pero-menos-responsa bles-de-trata-en-el-distrito-federal/>.

63 Embajada de Estados Unidos, Op. cit. 
las diversas instituciones y supervisión de la Auditoría Fiscal de la Federación. ${ }^{64}$

Por lo tanto, la Ley General en materia de trata de personas, por su ambigüedad y al estado de excepción determinado por ella promueven la aplicación de políticas públicas que basadas en el miedo construyen víctimas y victimarios dentro del sector que se considera puede estar vinculado con la trata de personas.

7. Séptima paradoja: El poder y el derecho entran en UNA RECURSIVIDAD QUE LOS IMPLICA A LOS DOS

La ley general contra la trata de personas reproduce y legitima poder, lo que implica el derecho a castigar.

9. El poder y el derecho entran en una recursividad que los implica a los dos. El poder inventa la ideología-derecho que le sirve para su legitimación y su reproducción. El poder produce derecho, tanto cuanto el derecho re-produce poder, en una interacción recursiva que los conjunta en el derecho a castigar. ${ }^{65}$

Lo anterior se traduce en que el derecho está vinculado con la clase poderosa que lo produce. De esta manera, el derecho no se crea para beneficio de los ciudadanos, en términos de democracia. Lo que sucede es que el derecho es creado para legitimar al poderoso a llevar a cabo acciones violentas pero legitimas gracias al propio derecho.

Ya antes se había dicho en la segunda paradoja que la ley está construida a partir de los intereses políticos de quien la creó. Ahora, hay que agregar que no solo es la construcción epistemológica en la

64 Cfr. Adriana Dávila Fernández, Análisis del Informe 2015 de la Comisión Intersecretarial para Prevenir, Sancionar y Erradicar los Delitos en Materia de Trata de Personas. Consultado en: <http://www.senado.gob.mx/comisiones/trata_personas/docs/ presentacion.pdf $>$.

65 Augusto Sánchez Sandoval, op. cit., p. 205. 
construcción de la ley, sino de a quién se dirige la ley. De esta forma, los objetivos de la ley no están encaminados a resolver un problema social, sino a legitimar a quienes ocupan posiciones de poder y sus acciones represivas:

CIUDAD DE MÉXICO (apro).- El secretario de Gobernación, Alfonso Navarrete Prida, anunció la creación de un operativo similar al del Escudo Titán, con el fin de capturar a las personas dedicadas a la trata de personas en varios estados del país, principalmente en los del sureste, donde - dijo - este delito se ha agravado.

En conferencia de prensa, realizada con motivo del Día Mundial contra la Trata de Personas, también señaló que acaba de instruir a diversas áreas de la dependencia que encabeza, relacionadas con seguridad y migración, a "coordinar esfuerzos" y realizar "acciones más contundentes" para combatir la trata de personas. ${ }^{66}$

Esta clase de acciones son importantes para el sistema político por efecto cognitivo que tienen en la opinión pública. Así, aunque se viole el principio de presunción de inocencia de los detenidos, la sociedad puede percibir que el Gobierno sí hace algo efectivo para erradicar la trata de personas, es decir, las acciones ahí están:

Los constructores del derecho lo muestran como un conjunto de normas cuyo contenido es bien intencionado y democrático, pero dado que es ideología, hay que valorarlo por los resultados latentes y reales que alcanza, más que por la posible bondad que declara su texto. ${ }^{67}$

Ya se ha comentado que la ley no cumple con sus objetivos. De hecho es muy probable que nunca los cumpla dada la complejidad y magnitud del problema. No obstante, el tema sí es utilizado para los efectos de propaganda política que se requieren para construir esa realidad artificial en donde sí se combate al delito:

66 Rodrigo Vera, Navarrete Prida anuncia operativo contra la trata de personas en Proceso, México, 31 dejulio de 2018. Consultado en: <https:/ /www.proceso.com. $\mathrm{mx} / 545145$ /navarrete-prida-anuncia-operativo-contra-la-trata-de-personas $>$.

67 Augusto Sánchez Sandoval, op. cit., p. 205. 
Con motivo de la conmemoración del Día Mundial contra la Trata de Personas, la Secretaría de Gobernación a través de la Comisión Intersecretarial para Prevenir Sancionar y Erradicar los Delitos de Trata de Personas y para la Protección y Asistencia a las Víctimas de estos Delitos en conjunto con otras Dependencias y Organizaciones de la Sociedad Civil, han organizado diversos eventos, con el fin de generar conciencia y difundir información acerca este tema; entre los que se encuentran, la develación de un Boleto Conmemorativo del Sistema de Transporte Colectivo (METRo), Conversatorio: Intervención en la Trata de Personas en México, el Ciclotón de la Ciudad de México, una Feria informativa, Cultural y Deportiva, la cancelación de un Timbre Postal y el Sorteo Mayor de la Lotería Nacional con un Billete Conmemorativo. ${ }^{68}$

De hecho si se revisan las estadísticas que año con año presenta la Comisión Intersecretarial en la materia, se observa que en México sí se llevan a cabo acciones para avanzar en el problema. Pero, entonces, al subsistir e incluso aumentar los casos de trata de personas en México, quiere decir que tales acciones no tienen el efecto social deseado; sin embargo, el discurso político insiste en acciones simbólicas como la del billete de lotería y las otras mencionadas en la cita anterior.

Por ello, es posible decir que la ley general contra la trata de personas reproduce y legitima poder, lo que implica el derecho a castigar. Es una ley que legitima el abuso del poder por el cual se violan los derechos humanos tanto de inculpados como de víctimas:

No obstante, el gobierno no cumplió con las normas mínimas en varios ámbitos. La complicidad de las autoridades siguió siendo un grave problema que, en gran medida, seguía sin abordarse. El gobierno identificó menos víctimas y prestó servicios especializados limitados a las víctimas de trata identificadas. Los albergues siguieron siendo insuficientes para la magnitud del problema y no había

68 SEGOB, ¿Sabías que existe un día mundial contra la \#TrataDePersonas? 29 de julio de 2018. Consultado en: <https://www.gob.mx/segob/articulos/ sabias-que-existe-un-dia-mundial-contra-la-tratadepersonas?idiom $=\mathrm{es}>$. 
servicios para las víctimas en gran parte del país, por lo que algunas víctimas eran vulnerables a ser explotadas nuevamente. ${ }^{69}$

En conclusión, La ley contra la trata de personas y el poder entran en una recursividad que los implica a los dos y los convierte en la mismo cosa, toda vez que su discurso está orientado a legitimar las acciones simbólicas del sistema político.

8. Octava paradoja: El derecho es ideología y por lo TANTO OCULTA SU ORIGEN COMO CONSTRUCTOR DE PAUTAS PARA EXCLUIR

La ley contra la trata de personas como es represiva impone pautas de exclusión para seleccionar a aquellas personas qué pueden ser detenidas y sujetas a un proceso, por ejemplo bailarinas, trabajadores de centros nocturnos y criminaliza pobreza:

10. El derecho es ideología y por lo tanto oculta su origen como constructor de pautas para excluir. Por ello es un sistema que no puede ser democrático, porque para ser, requiere construir a su contrario, como no ser. Para existir la norma-lidad, se tiene que inventar la a-normalidad. ${ }^{70}$

Ya con anterioridad en la sexta paradoja, se dijo que derivado del contenido la ley y la necesidad de contar con estadísticas a favor, la autoridad emplea políticas represivas en las que trabajadores de centros nocturnos, bailarinas y, en general personas que trabajan en lugares etiquetados como propicios para la trata de personas y

69 El gobierno disminuyó las labores de protección, ya que identificó menos víctimas y prestó servicios especializados limitados a las víctimas de trata identificadas. Fuentes oficiales indicaron haber identificado a 740 víctimas de la trata en 2016: de ellas, 707 habían sido sometidas a la trata sexual, 15 al trabajo forzoso, 14 a la delincuencia forzosa, dos a condiciones de esclavitud, una a esclavitud y una a mendicidad forzada. Cfr. Embajada de los Estados Unidos en México, op. cit..

70 Augusto Sánchez Sandoval, op. cit., 209. 
explotación sexual a quienes se les viola su derecho de presunción de inocencia.

El problema no queda ahí, sino que existen otros casos en dónde se criminaliza la pobreza. Así, las autoridades detienen a prostitutas y a migrantes como si fueran tratantes o explotadores. ${ }^{71}$ Lo anterior coincide con lo señalado por HIP, cuyo estudio refiere que existen agricultores que por la necesidad de trabajo aceptan condiciones laborales menores a las establecidas por la Ley Federal del Trabajo y que la ley les considera víctimas de trata aunque en realidad no hay delito alguno en razón de que el trabajador es libre y está consciente de las condiciones laborales. ${ }^{72}$

De esta manera, las políticas públicas derivadas de la ley en materia de trata de personas son represivas, pero además establecen pautas de exclusión ya que tal represión está enfocada a ciertos sectores de sociales en dónde es más fácil la construcción discursiva de víctimas o tratantes.

\section{iv. Comentario final}

En este documento se ha comprobado que la hipótesis de que la ley general en materia de trata de personas es una paradoja ya que le da sentido a la fallida política criminal en materia de trata de personas la cual viola derechos humanos y no resuelve la problemática.

La ley general en materia de trata de personas pertenece al mundo del deber ser, lo que implica solo la creación de expectativas cuya materialización es contingente al estar referidas al futuro y por ello no cumple sus objetivos sobre erradicación, investigación, persecución y sanción de los delitos en materia de trata de personas.

Además, cómo cualquier ley, su construcción está sometida y determinada por intereses políticos. La consecuencia es que el delito de trata de personas está mal definido; sin embargo, aunque a ley

71 Embajada de los Estados Unidos en México, op. cit.

72 Hispanics in philanthrop, op. cit., p. 12. 
flexibilizó su redacción para facilitar las investigaciones, no cumple con sus objetivos sobre erradicación, investigación, persecución y sanción de los delitos en materia de trata de personas.

Por ello, su contenido y sus resultados son un sin sentido, ya que, en tanto derecho, no puede controlar su contenido al estar construida a partir de los intereses de actores políticos, lo cuales construyen una realidad en torno a su eficacia. Lo que sí hay es un derecho penal que legaliza las políticas públicas represivas y violadoras de derechos humanos, pero esa artificialidad es buena porque en ella se combate con eficacia la trata de personas, aunque a la vista de todos hay trata y explotación en todos lados.

Si no se previene y erradica el delito, si no se atiende a las víctimas como la ley mandata, si muchas víctimas son construidas gracias al miedo, si los sospechosos son detenidos en una franca violación a los principios de seguridad jurídica y presunción de inocencia y, además, la ley es excluyente, entonces su existencia no tiene sentido más que como reproductora de poder.

\section{v. Conclusiones}

Se ha comprobado la hipótesis de que: La Ley General en materia de trata de personas es una paradoja ya que le da sentido a la fallida política criminal en materia de trata de personas la cual viola derechos humanos y no resuelve la problemática por las siguientes paradojas:

PRIMERA: La ley general contra la de trata de personas pertenece al mundo del deber ser, lo que implica solo la creación de expectativas cuya materialización es contingente al estar referidas al futuro y por ello no puede garantizar el cumplimiento de sus objetivos sobre erradicación, investigación, persecución y sanción de los delitos en materia de trata de personas.

SEGUNDA: El delito de trata de personas contenido en la ley general está mal definido toda vez que fue creado con base en los inte- 
reses de los actores políticos que la crearon; sin embargo, aunque a ley flexibilizó la descripción típica del delito de trata para facilitar las investigaciones, no cumple con sus objetivos sobre erradicación, investigación, persecución y sanción de los delitos en materia de trata de personas.

TERGERA: El contenido de la Ley general contra la trata de personas cuyo objetivo es Prevenir, Sancionar y Erradicar los Delitos en Materia de Trata de Personas y para la Protección y Asistencia a las Víctimas es un sin sentido, ya que, en tanto derecho, no puede controlar su contenido al estar construida a partir de los intereses de actores políticos, lo cuales construyen una realidad en torno a su eficacia.

CUARTA: La ley general contra la trata de personas dados su objetivos políticos de prevenir y erradicar el delito, es un derecho penal construido para justificar las políticas públicas represivas y violadoras de derechos humanos que construyen un mundo artificial en el que se combate con eficacia la trata de personas.

QUINTA: La ley general contra la trata de personas es un discurso que gracias a los intereses del sistema político crea un estado de excepción que se traduce en la suspensión de los derechos humanos de quienes resultan simples sospechosos de cometer un tipo penal ambiguo y con ello se viola el principio de presunción de inocencia.

SEXTA: La Ley general contra la trata de personas, por su ambigüedad y al estado de excepción determinado por ella promueven la aplicación de políticas públicas que basadas en el miedo construyen víctimas y victimarios dentro del sector que se considera puede estar vinculado con la trata de personas.

SÉPTIMA: La ley general contra la trata de personas y el poder entran en una recursividad que la implica con el poder y lo convierte en la mismo cosa, toda vez que su discurso está orientado a legitimar las acciones simbólicas del sistema político.

OcTAVA: Las políticas públicas derivadas de la ley en materia de trata de personas son represivas, pero además establecen pautas de 
exclusión ya que tal represión está enfocada a ciertos sectores de sociales en dónde es más fácil la construcción discursiva de víctimas o tratantes.

\section{Vi. Fuentes}

\section{Bibliografía}

Ackerman, John, El mito de la transición democrática, México, Planeta, 2015. Amnistía Internacional, Informe 2017/18: La situación de los derechos humanos en el mundo. Consultado el 15 de julio de 2018 en: <https://www.amnesty.org/es/latest/research/2018/02/ann ual-report-201718/>.

Ávila, María Elena, et al., Victimización, percepción de inseguridad y cambios en las rutinas cotidianas en México en Revista de Saúde Pública, 50, 60. Epub October 03, 2016.

Amparo en revisión 79/2012. 28 de junio de 2012. Unanimidad de votos. Noveno Tribunal Colegiado en Materia Penal del Primer Circuito, Ponente: Emma Meza Fonseca. Secretaria: María del Carmen Campos Bedolla.

Cárdenas gracia, Jaime Fernando, El modelo jurídico del neoliberalismo, México, Instituto de Investigaciones Jurídicas de la UNAM, 2016.

— El proceso electoral de 2006 y las reformas electorales necesarias en Revista Mexicana de Derecho Constitucional, México, Número 16 Enero - Junio 2007, Instituto de Investigaciones Jurídicas-UNAM.

— L L crisis del sistema electoral mexicano: a propósito del proceso electoral 2012, México, UNAM, 2016.

Comisión Interamericana de Derechos Humanos, Reporte Situación de derechos humanos en México 2015, CIDH.

Comisión Nacional de los Derechos Humanos, Diagnóstico sobre la situación de la trata de personas en México, México, CNDH, 2013.

Cooney, Paul, Dos décadas de Neoliberalismo en México: resultados y retos en Novos Cadenos, NAEA, volumen 11, num. 2. 
Dávila Fernández, Adriana, Análisis del Informe 2015 de la Comisión Intersecretarial para Prevenir, Sancionar y Erradicar los Delitos en Materia de Trata de Personas. Consultado en: <http://www.senado.gob.mx/comisiones/trata_personas/docs/presentacion.pdf $>$.

Embajada de Estados Unidos en México, Reporte sobre Tráfico de Personas 2018, Consultado el 20 de julio de 2018 en: <https:// mx.usembassy.gov/es/our-relationship-es/reportes-oficiales/repo rte-sobre-trafico-de-personas $/>$.

- Reporte sobre Tráfico de Personas 2017. Consultado el 20 de julio de 2018 en: <https://mx.usembassy.gov/es/our-relationship-es/ reportes-oficiales/reporte-sobre-trafico-de-personas/>.

Estrada Michel, Rafael, Prologo en Aspectos sociales y culturales de la trata de personas en México, Coord: Casillas, Rodolfo R. Instituto Nacional de Ciencias Penales, 2013.

Fernández Ruiz, Jorge, El Poder Legislativo, México, Porrúa-UNAM, 2004.

FERRAJOLI, Luigi, Jurisdicción y ejecución penal. La cárcel: una contradicción institucional en Crítica Penal y Poder num: 11, OSPDH-Universidad de Barcelona 11, 2016.

Gaceta del Semanario Judicial de la Federación, Libro 3, Ejecutoria de la Acción de inconstitucionalidad 54/2012 promovida por la Procuradora General de la República, Décima Época. Pleno. Febrero de 2014, Tomo I, Pág. 123. Registro 24831.

González Vidaurri, Alicia y SÁNCHEZ SANDOVAL, Augusto Criminología, México, Porrúa, 2013.

Gunther, Jakobs, Moderna Dogmática penal, México, Porrua, 2006.

Hassemer, Winfried, Derecho penal simbólico y protección de bienes jurídicos, Pena y Estado, Jurídica Conosur, 1995.

Hispanics in philanthrop, Una Mirada desde las organizaciones de la sociedad civil a la Trata de personas en México, Coord. Mónica Salazar, HIP, Consultado en: <http://www.senado.gob.mx/comisiones/trata_personas/docs/trata.pdf $>$.

KLein Naomi y Fuentes García, Isabel, La doctrina del shock: el auge del capitalismo del desastre, Barcelona: Paidós, 2007. 
Luhmann, Niklas, El derecho de la sociedad, México: Herder - Universidad Iberoamericana, 2005.

Nafarrete Torres, Javier, Niklas Luhmann, La politica como sistema, México: Universidad Iberoamericana, 2009.

Ontiveros Alonso, Miguel, El derecho penal frente a la trata de personas (problemas técnicos y político criminales) en <https://archivos.juridicas.unam. $\mathrm{mx} / \mathrm{www} / \mathrm{bjv} / \mathrm{libros} / 7 / 3064 / 16 . p d f>$.

Onude Oficina de las Naciones Unidas contra las Drogas y el Delito, Human Trafficking, Consultado el 18 de julio de 2018 en: <https:// www.unodc.org/unodc/en/human-trafficking/what-is-human-tra fficking.html>.

—- Informe Global sobre Trata de Personas 2016, Viena, ONU, 2016.

- Checklist Criminazalization of Human Traffiking under the Protocol: <http://www.unodc.org/documents/human-trafficking/Chec klist $\% 20-\% 20$ criminalization $\% 20$ under $\% 20$ the $\% 20$ Protocol.pdf>.

- Human Traffiking: <http://www.unodc.org/unodc/en/human-tra fficking/what-is-human-trafficking.html?ref=menuside $>$.

Polaino y OrTs, Criminalidad organizada: fundamentos dogmáticos y límites normativos (con referencia a la Ley Federal mexicana contra la delincuencia organizada) en: Criminalidad organizada, formas de combate mediante el derecho penal, México, Flores.

Roxin, Claus, Derecho penal. Parte general. Fundamentos. La estructura de la teoría del delito, Thomson Civitas, Madrid, 2008.

Rangel Cortés, Víctor Manuel, La ley contra la trata de personas en el sistema jurídico mexicano, Comisión Contra la Trata de Personas, Senado de la República. Consultado el 29 de julio de 2018 en: <http://www. senado.gob.mx/comisiones/trata_personas/docs/info_reformas5. $\operatorname{pdf}>$.

SCJN, Acción de inconstitucionalidad 54/2012. Procuradora General de la República. 31 de octubre de 2013.

Sánchez sandoval, Augusto, Seguridad Nacional y Derechos Humanos, México, Facultad de Estudios Superiores Acatlán de la UNAM, 2013. 
—- Epistemologías y sociología jurídica del poder, México, UNAM-FES Acatlán, 2012.

Semanario Judicial de la Federación XXV, Registro: 172739, Instancia: Pleno, Materia(s): Constitucional, Tesis Aislada, Novena Época, Abril de 2007, Tesis: P. VII/2007, p. 5).

Semanario Judicial de la Federación y su Gaceta Libro XV, Época: Décima Época, Registro: 2002428, Instancia: Tribunales Colegiados de Circuito, Tipo de Tesis: Aislada, Diciembre de 2012, Tomo 2, Materia(s): Penal, Tesis: I.9o.P.21 P (10a.) Página: 1580.

\section{Hemerografía}

GNNMéxico, El Senado aprueba reforma a ley contra la trata que amplía tipificaciones en GNN México, México, 12 de febrero de 2014. Consultado el 15 de julio de 2018 en: <https://expansion. $\mathrm{mx} / \mathrm{nacional} / 2014 / 02 / 12 /$ el-senado-aprueba-reforma-a-ley-contra-la-trata-que-amplia-tipificaciones $>$.

Monroy, Jorge, Acusan regresión en Ley de trata en El Economista, Ciudad de México, 01 de enero de 2017. Consultado el 29 de julio de 2018: <https://www.eleconomista.com.mx/politica/Acusan-regresion-en-Ley-de-Trata-20170101-0084.html>.

Orozco, Rosi, Avances contra la trata, Milenio, México, Ciudad de México, 08 enero de 2016, Consultado el 29 de julio de 2018 en: <http://w ww.milenio.com/opinion/rosi-orozco/columna-rosi-orozco/ avances-contra-la-trata>.

Torres Rubén y Monroy Jorge, México sin cifras precisas sobre trata en El economista, México, Ciudad de México, 30 de julio de 2017,. Consultado en: <https://www.eleconomista.com.mx/politica/Me xico-sin-cifras-precisas-sobre-trata-20170730-0073.html>.

Vera, Rodrigo, Navarrete Prida anuncia operativo contra la trata de personas en Proceso, México, 31 de julio de 2018. Consultado en: <https://www.proceso.com.mx/545145/navarrete-prida-anu ncia -operativo-contra-la-trata-de-personas $>$. 